\section{Structured Didactic Education Program for Writing Case Reports Can Motivate Medical Students}

About the Author: Yosuke To the Editor,

Kakisaka is a pediatrician

and epileptologist at To-

hoku University Graduate

school of Medicine in Sendai, Japan.

Submission: Oct 18, 2016 Acceptance: Oct 26, 2016 Publication: Oct 29, 2016

\section{Introduction}

As we described in our editorial in this issue, ${ }^{1}$ writing case reports is crucial in both building case writing skills and enhancing clinical diagnostic reasoning. Case reports have always been an integral part of medical history. ${ }^{2,3}$ However, case reporting instruction has previously tended to be vague, whereas students may need more detailed support such as step-by-step guidance. To address this issue, we recently launched an educational program, entitled "How to write a case report: Visualizing the trajectory from nothing to submission." The program consists of two parts: (1) a didactic lecture on the theoretical principles of case-writing, and (2) hands-on case report writing practice using a clinical case. The program is suitable for entry-level writers intending to make a submission to a journal. of our program and evaluates the motivational level of medical students towards case writing. The feasibility of structured education in case writing will also be discussed.

\section{Methods}

Eighteen medical students at Tohoku University School of Medicine participated in the program. The didactic part of the program is a one-hour lecture consisting of nine parts. After the lecture, the students were anonymously asked to evaluate the level of understanding on a self-reporting questionnaire developed by the authors. The intelligibility questionnaire for the lecture covered nine items. Each item is rated on a 4-point Likert-type scale: not understandable at all, less understandable, understandable, and very understandable. In this study, we focused on three selected parts, which are essential to understand the practical skills of case writing: (1) to read related case reports in order to deepen knowledge of the patient's condition; (2) to make a table to compare the current patient's symptoms with those in previously published case reports; and reportable significance as a case report. As an example of the product of this methodology, a past publication of the authors is shown in Table 1. The participants provided comments for qualitative evaluation and also assessed their motivation for writing case reports after the lecture.

\section{Results}

All 18 medical students answered the survey on the intelligibility part of the lecture, and 14 answered the motivation part. Table 2 shows the level of understanding for each step of the lecture. Approximately $90 \%$ of students rated each step as understandable or very understandable. No major concerns were raised regarding the quality of the contents. Positive comments were also given, such as "the lecture gave me generalized methods to make case reports." Several technical issues were raised, including "presentation speed is relatively fast," and "slides can be formatted better." Eleven of the 14 students responded "motivated" to the question of "are you motivated to write a case report?" The present article introduces the contents of the didactic part (3) to deliberate critically whether the choice of a topic has
Table 1. Clinical Profiles Comparison between Our Case and a Previous Case

\begin{tabular}{|c|c|c|c|c|}
\hline & Column 1 & Column 2 & Column 3 & Column 4 \\
\hline Row 0 & & Our case ${ }^{4}$ & Previous case ${ }^{5}$ & Comparison \\
\hline Row 1 & $\begin{array}{c}\text { Observed } \\
\text { phenomenon }\end{array}$ & $\begin{array}{l}\text { Psychiatric } \\
\text { symptom due to } \\
\text { CSF leakage }\end{array}$ & $\begin{array}{c}\text { Psychiatric } \\
\text { symptom due to } \\
\text { CSF leakage }\end{array}$ & Similar \\
\hline Row 2 & $\begin{array}{c}\text { Period } \\
\text { between } \\
\text { CSF leakage } \\
\text { and onset of } \\
\text { psychiatric } \\
\text { symptoms }\end{array}$ & 4 days & 40 days & Different \\
\hline Row 3 & $\begin{array}{l}\text { Psychiatric } \\
\text { symptoms }\end{array}$ & $\begin{array}{l}\text { Visual halluci- } \\
\text { nation }\end{array}$ & $\begin{array}{l}\text { Behavioral } \\
\text { dysfunction, } \\
\text { Disinhibition, } \\
\text { Impulsivity }\end{array}$ & Different \\
\hline Row 4 & $\begin{array}{l}\text { Imaging } \\
\text { study }\end{array}$ & No abnormalities & $\begin{array}{l}\text { Downward brain } \\
\text { displacement }\end{array}$ & Different \\
\hline Row 5 & $\begin{array}{l}\text { Recovery } \\
\text { time }\end{array}$ & One day & Several days & Different \\
\hline
\end{tabular}

The typical form of the comparison table consists of 4 columns and rows of various clinical factors (e.g., chief complaints, past and family history, present finding, laboratory data, imaging, clinical course, etc.). Each factor is compared between "our case" (the case being considered for a report) and "previous case(s)." Each clinical factor is marked as either "similar" or "different" in the last column. Clinical factors labeled as "different" are candidates for the main topic of the case report, and may represent a new finding, which is fundamental for significant scientific reports.

This table compares our case $\mathrm{e}^{4}$ and a previously published case $\mathrm{c}^{5}$ with psychiatric symptoms due to cerebrospinal fluid (CSF) leakage after lumbar puncture. The similarity is that both cases are examples of psychiatric symptoms due to CSF leakage (row 1), by which reproducibility of this phenomenon is warranted. Differences are seen in multiple characteristics (rows 2-5), implying the clinical and radiological diversity of this phenomenon. Our conclusion is that "presence and diversity of this rare phenomenon, psychiatric symptoms due to CSF leakage, should be considered for better patient management."

Table 2. Result of Intelligibility for Each Step of the Lecture

\begin{tabular}{|ccccc}
\hline Step & $\begin{array}{c}\text { Not understan- } \\
\text { dable at all }\end{array}$ & $\begin{array}{c}\text { Less unders- } \\
\text { tandable }\end{array}$ & $\begin{array}{c}\text { Understan- } \\
\text { dable }\end{array}$ & $\begin{array}{c}\text { Very unders- } \\
\text { tandable }\end{array}$ \\
\hline 1 & $0 \%(0)$ & $6 \%(1)$ & $11 \%(2)$ & $83 \%(15)$ \\
\hline 2 & $0 \%(0)$ & $0 \%(0)$ & $17 \%(3)$ & $83 \%(15)$ \\
3 & $0 \%(0)$ & $11 \%(2)$ & $22 \%(4)$ & $67 \%(12)$ \\
\hline
\end{tabular}

Parenthesis indicates number of responses.

\section{Discussion}

This preliminary study suggests that structured education for medical students on writing a case report is efficacious for the following reasons. First, the quality of the didactic education program was helpful for approximately $90 \%$ of the participating students. Second, approximately $80 \%$ of the students were motivated to write case reports after the lecture. The study is limited by the small sample size. Future study should consider expanding the sample size and implementing objective markers as an outcome.

Yosuke Kakisaka, ${ }^{1,2}$ Mayu Fujikawa, ' Schuyler Gaillard. ${ }^{3}$ ' Department of Epileptology, Tohoku University Graduate School of Medicine, Sendai, Miyagi, Japan.

2 Department of Pediatrics, Tohoku University Graduate School of Medicine, Sendai, Miyagi, Japan.

${ }^{3}$ Department of Brain and Cognitive Sciences, Massachusetts Institute of Technology, Cambridge, MA, USA. 
Correspondence: Yosuke Kakisaka.

Address: Department of Epileptology, Tohoku University Graduate School of Medicine, 2-1 Seiryo-machi, Aoba-ku, Sendai, Miyagi $980-$ 8575, Japan.

Email: kakisuke@mui.biglobe.ne.jp

\section{References}

1. Kakisaka $Y$, Fujikawa M, Gaillard S. Writing case reports: teaching and tuition techniques, and the improvement of clinical diagnostic reasoning. Int J Med Students. 2016 Sep-Dec;4(3):88-90.

2. Nield LS. Writing case reports for the clinical literature: practical approach for the novice author. J Grad Med Educ. 2011 Sep;3(3):445.

3. Juyal $D$, Thaledi $S$, Thawani V. Writing patient case reports for publication. Educ Health (Abingdon). 2013 May-Aug;26(2):126-9.

4. Kakisaka Y, Hino-Fukuyo N, Kobayashi T, Kubota Y, Kikuchi A, Endo W, et al. Hallucinations associated with cerebrospinal fluid leakage after a lumbar puncture. Br J Anaesth. 2012 Sep;109(3):465-6; author reply 466.

5. Loures V, Savoldelli GL, Alberque C, Haller G. Post-dural puncture cerebrospinal fluid leak presenting as an acute psychiatric illness. $\mathrm{Br}$ J Anaesth. 2012 Mar;108(3):529-30.

\section{Acknowledgments: None.}

Conflict of Interest Statement it Funding: The authors have no funding, financial relationships, or conflicts of interest to disclose.

Author Contributions: Conceptualization: YK. Writing, Critical revision of the manuscript, Approval of the final version: YK, MF, SG.

Cite as: Kakisaka Y, Fujikawa M, Gaillard S. Structured didactic education program for writing case reports can motivate medical students. Int J Med Students. 2016 Sep-Dec;4(3):131-2.

\section{Latin America: Should We Be Worried about Zika Virus?}

About the Author: Joselyn $\gamma e$ is currently a fifth-yea medical student at Cayetano Heredia University, Lima, Peru of a seven-year program

Submission: Sep 17, 2016 Acceptance: Nov 14, 2016 Publication: Dec 24, 2016

\section{To the Editor}

The Zika virus (ZIKV) was identified for the first time in 1947, almost 70 years ago. Despite being known during all these decades, it has been neglected until the current outbreak in Brazil. This an emergent disease that has been developing slowly throughout these years; we still have limited information and scientific knowledge about this illness and its potential outcomes.

This infection causes fairly mild effects, as $80 \%$ of the patients go unnoticed. ${ }^{2}$ The most common symptoms are fever, rash, joint pain, and conjunctivitis, which last for several days to a week after the infection. ${ }^{3}$ The primary mode of transmission is through the bite of an infected mosquito of the Aedes species. Apart from mosquitoes, other non-vector means of transmission are sexual intercourse and during pregnancy. Furthermore, there is a strong possibility that ZIKV can be spread through blood transfusions. It is suggested that breastfeeding could be another way of transmission, due to the fact that it has been found in breast milk. However, there are no reports up to date about other means of transmission. Because of the benefits of breastfeeding, mothers are encouraged to breastfeed even in areas where ZIKV is found (Available from: http://www.cdc.gov/ zika/about/overview.html; cited 2016 Jul 28).

Since ZIKV can cross the blood brain barrier, ${ }^{4}$ a relationship with some severe congenital neurologic defects, such as mi- crocephaly and Guillian-Barré syndrome, has been established. Mlakar et al described that the cases of microcephaly increased by a factor of 20 among newborns in the northeast of Brazil. 4.5 Many other authors also describe severe brain injuries, inflammatory signs and calcifications, leading them to think that it is likely that an intrauterine infection brings about the abnormal brain development, and can lead to cerebral palsy after birth. ${ }^{1-3}$ It is also suggested that the low maternal supplementation of nutrients may affect other organs as well, ${ }^{6}$ although this is yet to be determined.

The World Health Organization declared ZIKV a 'Public Health Emergency of International Concern"; $;$ as it threatens to become a global pandemic. Up to date, there is no cure or vaccine available (Available from: http://www.cdc.gov/zika/about/overview.html; cited 2016 Jul 28). There are different methods for diagnosing ZIKV. One of them is the real-time reverse transcription-polymerase chain reaction (rRT-PCR), which must only be conducted on urine or serum samples collected during the first 14 days after symptoms onset. This test has a high sensitivity and a poor specificity. If the rRT-PCR is negative in a high risk patient, the ELISA for qualitative detection of IgM (Zika MAC-ELISA) is used. ${ }^{8}$ However, a cross-reaction with other flaviviruses is present, as such the test has poor specificity in people living in endemic areas that have been previously exposed to the dengue and yellow fever viruses. ${ }^{6-9}$ Therefore, results may be difficult to interpret in Latin America.

System-wide barriers impede health care delivery in our region. Latin American health providers have the obligation to generate awareness amongst our people about ZIKV. The need for a stronger surveillance system, suitable diagnostics methods, communication about ZIKV outbreak risks, vector control and adequate guidance to pregnant women is necessary. ${ }^{3}$

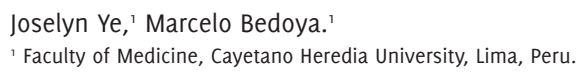

\section{References}

1. Schuler-Faccini L, Ribeiro EM, Feitosa IM, Horovitz DD, Cavalcanti DP, Pessoa $A$, et al. Possible association between zika virus infection and microcephaly Brazil 2015. MMWR Morb Mortal Wkly Rep. 2016 Jan;65(3):59-62.

2. Petersen E, Wilson ME, Touch S, McCloskey B, Mwaba P, Bates M, et al. Rapid spread of Zika virus in the Americas - implication for public health preparedness for mass gatherings at the 2016 Brazil Olympic Games. Int J Infect Dis. 2016 Mar;44:11-5.

3. Heymann DL, Hodgson A, Sall AA, Freedman DO, Staples JE, Althabe F, et al. Zika virus and microcephaly: why is this situation a PHEIC? Lancet. 2016 Feb 20;387(10020):719-21.

4. Tetro JA. Zika and microcephaly: causation, correlation, or coincidence? Microbes Infect. 2016 Mar;18(3):167-8.

5. Mlakar J, Korva M, Tul N, Popovic M, Poljsak-Prijatelj M, Mraz J, et al. Zika virus associated with microcephaly. N Engl J Med. 2016 Mar 10;374(10):951-8. 6. World Health Organization. WHO statement on the first meeting of the International Health Regulations. Emergency Committee on Zika virus and observed increase in neurological disorders and neonatal malformations; 2016.

7. Vogel G. Evidence grows for Zika virus as pregnancy danger. Science. 2016 